\title{
Relationship between the production of autoantibodies to oxidized low-density lipoprotein and hepatic steatosis in patients with chronic hepatitis $\mathbf{C}$
}

\author{
TAKASHI HIMOTO ${ }^{1,2}$, HIROHITO YONEYAMA ${ }^{1}$, AKIHIRO DEGUCHI $^{1}$, KAZUTAKA KUROKOHCHI $^{1}$, \\ MICHIO INUKAI ${ }^{2}$, HISASHI MASUGATA ${ }^{2}$, FUMINORI GODA ${ }^{2}$, SHOICHI SENDA ${ }^{2}$, \\ REIJI HABA ${ }^{3}$, SEISHIRO WATANABE ${ }^{4}$, MIKIO NISHIOKA ${ }^{1}$ and TSUTOMU MASAKI ${ }^{1}$
}

Departments of ${ }^{1}$ Gastroenterology and Neurology, ${ }^{2}$ Integrated Medicine, and ${ }^{3}$ Diagnostic Pathology,

Kagawa University School of Medicine; ${ }^{4}$ Department of Internal Medicine,

Kagawa Prefectural Central Hospital, Kagawa, Japan

Received March 4, 2010; Accepted May 31, 2010

DOI: 10.3892/etm_00000104

\begin{abstract}
Persistent hepatitis C virus (HCV) infection induces oxidative stress and eventually leads to hepatic steatosis. Oxidatively modified autoantigens, including oxidized lowdensity lipoprotein (ox-LDL), were identified in patients with systemic lupus erythematosus. Chronic HCV infection often evokes autoimmune phenomena, such as autoantibody production and/or concurrent autoimmune diseases. We examined the relationship between the production of antibodies to ox-LDL (anti-ox-LDL) and hepatic steatosis in patients with chronic hepatitis $\mathrm{C}(\mathrm{CH}-\mathrm{C})$. Anti-ox-LDL levels were determined by the enzyme-linked immunosorbent assay method. The severity of hepatic steatosis was evaluated using the classification proposed by Brunt and colleagues. The effect of antiviral treatment was also investigated. Twenty-two (52\%) of the 42 patients with $\mathrm{CH}-\mathrm{C}$ had no hepatic steatosis (grade $0)$, while $12(29 \%)$ and $8(19 \%)$ had grade 1 and 2 hepatic steatosis, respectively. The overall serum immunoglobulin $\mathrm{G}$ (IgG) level in patients with grade 2 steatosis was significantly higher than that in patients with grade 0 steatosis $(1,999 \pm 340$ vs. $1,465 \pm 196 \mathrm{mg} / \mathrm{dl}, \mathrm{p}<0.0001)$. The mean anti-ox-LDL level in grade 2 steatosis patients was also higher than that in grade 0 steatosis patients $(754 \pm 479$ vs. $361 \pm 274 \mathrm{mU} / \mathrm{ml}, \mathrm{p}=0.0165)$. A close correlation was apparent between anti-ox-LDL and serum IgG levels $(r=0.390, p=0.0107)$. There was no significant difference in the level of anti-ox-LDL between $\mathrm{CH}-\mathrm{C}$ patients who acquired sustained virological response (SVR) and those who exhibited non-SVR. These findings suggest that
\end{abstract}

Correspondence to: Dr Takashi Himoto, Department of Integrated Medicine, Kagawa University School of Medicine, 1750-1 Ikenobe, Miki-Cho, Kita-Gun, Kagawa 761-0793, Japan

E-mail: thimoto@med.kagawa-u.ac.jp

Key words: autoantibodies to oxidized low-density lipoprotein, autoimmune phenomena, hepatic steatosis, hepatitis C virus, oxidatively modified autoantigens
anti-ox-LDL in patients with $\mathrm{CH}-\mathrm{C}$ is induced in the process of hepatic steatosis and that the emergence of anti-ox-LDL does not affect antiviral treatment.

\section{Introduction}

Persistent hepatitis $\mathrm{C}$ virus (HCV) infection results in reactive oxygen species (ROS) in the liver $(1,2)$, and the oxidative stress induced by $\mathrm{HCV}$ infection leads to lipid peroxidation (3), eventually progressing to hepatic steatosis $(4,5)$.

Hepatic steatosis is usually observed, not only in patients with chronic hepatitis $\mathrm{C}(\mathrm{CH}-\mathrm{C})$, but also in those with alcoholism (6), obesity and diabetes mellitus (DM) (7), and patients who have undergone treatment with tetracycline or corticosteroid (8). Previous studies have found hepatic steatosis in approximately $30-70 \%$ of patients with $\mathrm{CH}-\mathrm{C}$ (9-16). The degree of hepatic steatosis in the majority of these patients was mild to moderate. The prevalence of severe hepatic steatosis, occupying more than $50 \%$ of hepatocytes, appears to be relatively low in patients with $\mathrm{CH}-\mathrm{C}$.

The clinical significance of hepatic steatosis in patients with CH-C has been well established. Obesity $(10-13,15)$, insulin resistance $(14,15)$, hepatic fibrosis $(9,12,13,16)$ and HCV genotype $3(10-13,16)$ are independently associated with hepatic steatosis upon multivariate analysis. Hepatic steatosis also appears to be a predictive hallmark of poor response to antiviral treatments in patients with $\mathrm{CH}-\mathrm{C}(16,17)$. In addition, hepatic steatosis may be a possible indicator of progression to hepatocellular carcinoma $(18,19)$.

Persistent HCV infection often evokes autoimmune phenomena, such as the production of numerous types of autoantibodies and/or concomitant autoimmune diseases $(20,21)$. Recent studies have revealed the identification of oxidatively modified autoantigens, including oxidized lowdensity lipoprotein (ox-LDL), from the sera of patients with systemic lupus erythematosus (SLE) (22) and type 1 DM (23). The main purpose of this study was to investigate whether an immune response to ox-LDL may be involved during the process of hepatic steatosis in patients with $\mathrm{CH}-\mathrm{C}$. 
Table I. Demographic characteristics of the enrolled patients with $\mathrm{CH}-\mathrm{C}$.

\begin{tabular}{lcccc}
\hline & \multicolumn{3}{c}{ Hepatic steatosis } & \\
\cline { 2 - 4 } & Grade 0 $(\mathrm{n}=22)$ & Grade 1 $(\mathrm{n}=12)$ & Grade 2 $(\mathrm{n}=8)$ & $\mathrm{p}$-value \\
\hline Age (years) & $57.8 \pm 13.3$ & $59.2 \pm 10.0$ & $63.4 \pm 9.1$ & $\mathrm{NS}$ \\
Gender (male/female) & $11 / 11$ & $6 / 6$ & $5 / 3$ & $\mathrm{NS}$ \\
HCVgenotype $(1 \mathrm{~b} / 2 \mathrm{a} / 2 \mathrm{~b})$ & $(13 / 6 / 3)$ & $(9 / 2 / 1)$ & $(4 / 3 / 1)$ & $\mathrm{NS}$ \\
Loads of HCV-RNA (KIU/ml) & $996 \pm 899$ & $1555.0 \pm 1519$ & $1,098.0 \pm 504$ & $\mathrm{NS}$ \\
BMI $\left(\mathrm{kg} / \mathrm{m}^{2}\right)$ & $22 \pm 2.8^{\mathrm{a}}$ & $23.3 \pm 2.6^{\mathrm{b}}$ & $27.2 \pm 3.7^{\mathrm{a}, \mathrm{b}}$ & $\mathrm{p}=0.0004^{\mathrm{a}}$ \\
Concurrent type 2 DM & $6(27 \%)$ & $1(8 \%)$ & $4(50 \%)$ & $\mathrm{p}=0.0115^{\mathrm{b}}$ \\
\hline
\end{tabular}

CH-C, chronic hepatitis C; HCV, hepatitis C virus; BMI, body mass index; DM, diabetes mellitus; NS, not significant.

\section{Materials and methods}

Study population. Forty-two patients who had detectable serum HCV-RNA by polymerase chain reaction (PCR) and showed histological findings compatible with $\mathrm{CH}-\mathrm{C}$ were randomly selected for participation in this study. Administration of pegylated interferon (PEG-IFN) alone or PEG-IFN plus ribavirin was carried out for 24 or 48 weeks in all of the enrolled patients after percutaneous liver biopsy. The evaluation of the antiviral treatment was carried out in 34 of the 42 patients with $\mathrm{CH}-\mathrm{C}$.

Clinical assessments. Age at entry, gender and the prevalence of type $2 \mathrm{DM}$ were examined in the enrolled patients. Obesity was evaluated by body mass index (BMI) which was calculated in accordance with the formula: weight $(\mathrm{kg})$ divided by height $^{2}\left(\mathrm{~m}^{2}\right)$.

Laboratory assessments. Anti-ox-LDL levels were determined using commercially available enzyme-linked immunosorbent assay (ELISA) kits (Biomedica, Vienna, Austria). Biochemical tests, including analysis of alanine aminotransferase (ALT), total choresterol (T-Cho) and triglyceride (TG) levels, were carried out before the antiviral treatment. Insulin resistance was determined by the Homeostasis Model for Assessment of Insulin Resistance (HOMA-IR) method using the following equation: HOMA-IR = fasting insulin $(\mu \mathrm{U} /$ $\mathrm{ml}) \mathrm{x}$ fasting glucose $(\mathrm{mg} / \mathrm{dl}) / 405$. Quantitative detection of serum HCV-RNA was performed by the Amplicor-HCV monitor assay (Roche Molecular Diagnostics, Tokyo, Japan) (24). The HCV genotype was determined by the HCV-RNA genotyping assay system (Home Brew SRL Inc., Tokyo, Japan) (25). Sustained viral response (SVR) was defined as an absence of HCV-RNA in serum 24 weeks after the completion of the treatment. No biochemical or virological response to the treatment was regarded as non-SVR. As immunoserological assessments, antinuclear antibody (ANA) and serum immunoglobulin $\mathrm{G}(\mathrm{IgG})$ levels were measured. ANA was tested at a serum dilution of 1:40 by the indirect immunofluorescence method using HEp-2 cells as substrates. Positive reactions were titered by double dilution to the end point.
Histological assessments. Liver tissue specimens were obtained by liver biopsy under the guidance of ultrasound using 16-gauge needles before treatment. The tissue samples were fixed in $10 \%$ formalin and embedded in paraffin. The tissue sections were stained with H\&E for morphological evaluation. The severity of hepatic steatosis was graded on the basis of the classification proposed by Brunt and colleagues (26). Briefly, steatosis observed in none, $<33,33-66$ or $>66 \%$ of hepatocytes was defined as grades $0,1,2$ or 3 , respectively. Fibrosis and necroinflammation in the liver were evaluated in accordance with the New Inuyama Classification system (27) and the histological activity index (HAI) scores designed by Knodell et al (28). The staging of hepatic fibrosis was classified from F0 to F4. F0 was defined as no fibrosis in the tissue specimen, while F4 was defined as liver cirrhosis.

Statistical analyses. Data values are represented as the mean \pm standard deviation (SD). The Mann-Whitney U test was applied for comparison of continuous variables. Linear regression analysis was used to analyze the relationships between titers of anti-ox-LDL and serum IgG, ALT levels or values of HOMA-IR. We used the Fisher's exact test to compare the differences in frequencies. p-values of $<0.05$ were considered to indicate a significant difference between groups.

\section{Results}

Demographic features of the enrolled patients with $\mathrm{CH}-\mathrm{C}$. Among the enrolled patients, 22 cases were male and 20 were female. HCV genotypes of the enrolled patients were $1 \mathrm{~b}$ in $26(62 \%)$ patients, $2 \mathrm{a}$ in $11(26 \%)$ and $2 \mathrm{~b}$ in $5(12 \%)$ patients. The ages at entry in the enrolled patients ranged from 23 to 76 years.

As shown in Table I, 22 (52\%) of the 42 patients with CH-C had no hepatic steatosis (grade 0 ), while $12(29 \%)$ patients had hepatic steatosis of grade 1 and $8(19 \%)$ of grade 2 . None of the patients showed grade 3 hepatic steatosis. There were no significant differences in age or gender between $\mathrm{CH}-\mathrm{C}$ patients with grade 0,1 or 2 hepatic steatosis. The prevalence of concurrent type $2 \mathrm{DM}$ in $\mathrm{CH}-\mathrm{C}$ patients with grade 2 hepatic steatosis was higher than that in the other groups, although no significant differences were apparent. The mean BMI in the 
Table II. Laboratory data of the patients according to hepatic steatosis group.

\begin{tabular}{|c|c|c|c|c|}
\hline & \multicolumn{3}{|c|}{ Hepatic steatosis } & \multirow[b]{2}{*}{ p-value } \\
\hline & Grade $0(n=22)$ & Grade $1(n=12)$ & Grade $2(n=8)$ & \\
\hline ALT (IU/1) & $81 \pm 64$ & $69 \pm 37$ & $112 \pm 66$ & NS \\
\hline $\mathrm{TG}(\mathrm{mg} / \mathrm{dl})$ & $89 \pm 40$ & $89 \pm 35$ & $118 \pm 35$ & NS \\
\hline T-Cho (mg/dl) & $157 \pm 39$ & $162 \pm 29$ & $162 \pm 39$ & NS \\
\hline $\mathrm{IgG}(\mathrm{mg} / \mathrm{dl})$ & $1,465 \pm 196^{\mathrm{a}, \mathrm{b}}$ & $1,868 \pm 382^{\mathrm{a}}$ & $1,999 \pm 340^{\mathrm{b}}$ & $\begin{array}{l}\mathrm{p}=0.0003^{\mathrm{a}} \\
\mathrm{p}<0.0001^{b}\end{array}$ \\
\hline Prevalence of ANA & $5(23 \%)$ & $4(33 \%)$ & $4(50 \%)$ & NS \\
\hline
\end{tabular}

ALT, alanine aminotransferase; TG, triglyceride; T-Cho, total choresterol; IgG, immunoglobulin G; ANA, antinuclear antibodies; NS, not significant.

grade 2 group was significantly higher than that in the grade 0 group $(27.2 \pm 3.7$ vs. $22.0 \pm 2.8, \mathrm{p}=0.0004)$ and that in the grade 1 group $(27.2 \pm 3.7$ vs. $23.3 \pm 2.6, \mathrm{p}=0.0115)$. The severity of hepatic steatosis was independent of HCV genotypes and loads of HCV-RNA (data not shown).

Correlation of hepatic steatosis with laboratory findings in patients with $\mathrm{CH}$ - $\mathrm{C}$. Table II summarizes the values of the biochemical and immunological parameters measured in each group. There were no significant differences in serum ALT, T-Cho or TG levels among the three groups. CH-C patients with grade 1 or 2 hepatic steatosis had significantly higher values of serum $\operatorname{IgG}$ levels than those with grade 0 hepatic steatosis $(1,868 \pm 382$ vs. $1,465 \pm 196 \mathrm{mg} / \mathrm{dl}, \mathrm{p}=0.0003$; $1,999 \pm 340$ vs. $1,465 \pm 196 \mathrm{mg} / \mathrm{dl}, \mathrm{p}<0.0001)$. The prevalence of ANA in $\mathrm{CH}-\mathrm{C}$ patients with grade 2 hepatic steatosis was higher than ANA in the other groups, although no significant differences were found among the three groups.

Correlation of hepatic steatosis with anti-ox-LDL. The levels of anti-ox-LDL in each group are shown in Fig. 1. The mean titer of anti-ox-LDL in patients with grade 2 hepatic steatosis was significantly higher than that in patients with grade 0 hepatic steatosis $(754 \pm 479$ vs. $361 \pm 274 \mathrm{mU} / \mathrm{ml}, \mathrm{p}=0.0165)$. Fig. 2A demonstrates the close correlation between titers of anti-ox-LDL and serum IgG levels ( $\mathrm{r}=0.390, \mathrm{p}=0.0107$ ). However, the titers of this autoantibody were not associated with serum ALT levels $(r=0.208, p=0.1865)$ or values of HOMA-IR ( $\mathrm{r}=0.192, \mathrm{p}=0.2627)$, as shown in Fig. $2 \mathrm{~B}$ and $\mathrm{C}$, respectively.

Relationship between titers of anti-ox-LDL and concurrent type $2 \mathrm{DM}$. The levels of anti-ox-LDL in $\mathrm{CH}-\mathrm{C}$ patients with type $2 \mathrm{DM}$ were compared to those in $\mathrm{CH}-\mathrm{C}$ patients without type 2 DM. As shown in Fig. 3, there was no significant difference in the levels of the autoantibodies between $\mathrm{CH}-\mathrm{C}$ patients

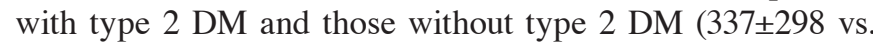
$497 \pm 376 \mathrm{mU} / \mathrm{ml}, \mathrm{p}=0.2518$ ).

Relationship between the titers of anti-ox-LDL and the effect of antiviral treatment. The effect of antiviral treatment was evaluated in 20 patients with $\mathrm{CH}-\mathrm{C}$ of genotype $1 \mathrm{~b}$ and 14 patients with $\mathrm{CH}-\mathrm{C}$ of genotype $2 \mathrm{a} / 2 \mathrm{~b}$. Among patients with

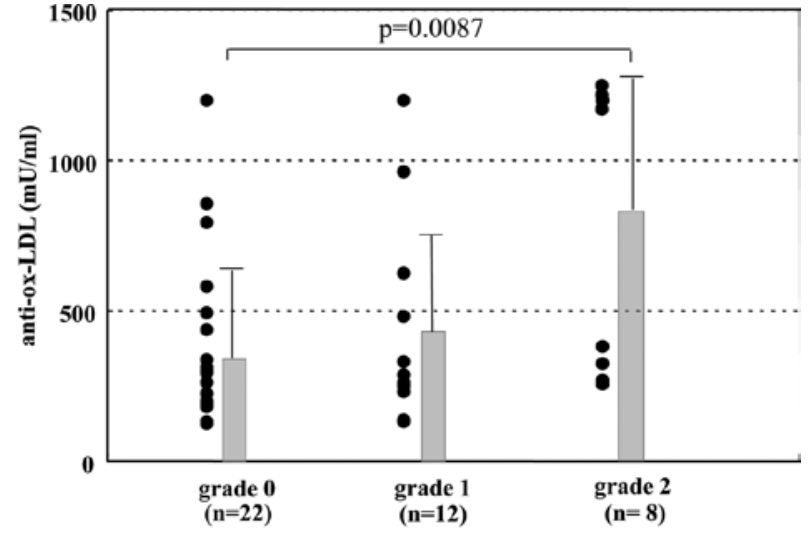

Figure 1. Relationship between the severity of hepatic steatosis and the levels of anti-ox-LDL.

CH-C of genotype $1 \mathrm{~b}, 2(25 \%)$ of 8 patients with grade 0 hepatic steatosis and $3(38 \%)$ of 8 patients with grade 1 hepatic steatosis acquired SVR, while none $(0 \%)$ of those with grade 2 hepatic steatosis did. The frequency of F3 in patients with $\mathrm{CH}-\mathrm{C}$ of genotype $1 \mathrm{~b}$ who acquired SVR was significantly lower than those who exhibited non-SVR (20 vs. $80 \%, \mathrm{p}=0.0176$ ), which suggests that hepatic fibrosis affected the outcome of antiviral treatment in patients with $\mathrm{CH}-\mathrm{C}$ of genotype $1 \mathrm{~b}$ (Table III). However, there was no significant difference in the levels of anti-ox-LDL between patients who acquired SVR and those who showed non-SVR (273 \pm 118 vs. $521 \pm 424 \mathrm{mU} / \mathrm{ml}, \mathrm{p}=0.2204$ ) (Table III). On the other hand, the levels of anti-ox-LDL were also independent of the effect of antiviral treatment in $\mathrm{CH}-\mathrm{C}$ patients of genotype $2 \mathrm{a} / 2 \mathrm{~b}$ $(477 \pm 376 \mathrm{mU} / \mathrm{ml}$ in the SVR group vs. $554 \pm 232 \mathrm{mU} / \mathrm{ml}$ in the non-SVR group, $\mathrm{p}=0.2424)$.

\section{Discussion}

In this study, we demonstrated that the degree of hepatic steatosis was significantly associated with the elevation of serum IgG levels (Table II) and anti-ox-LDL levels (Fig. 1) in patients with $\mathrm{CH}-\mathrm{C}$, which indicated that these autoantibodies were produced during the process of hepatic steatosis. These autoimmune responses were independent of HCV genotypes and loads of HCV-RNA, which suggests that host factors may 

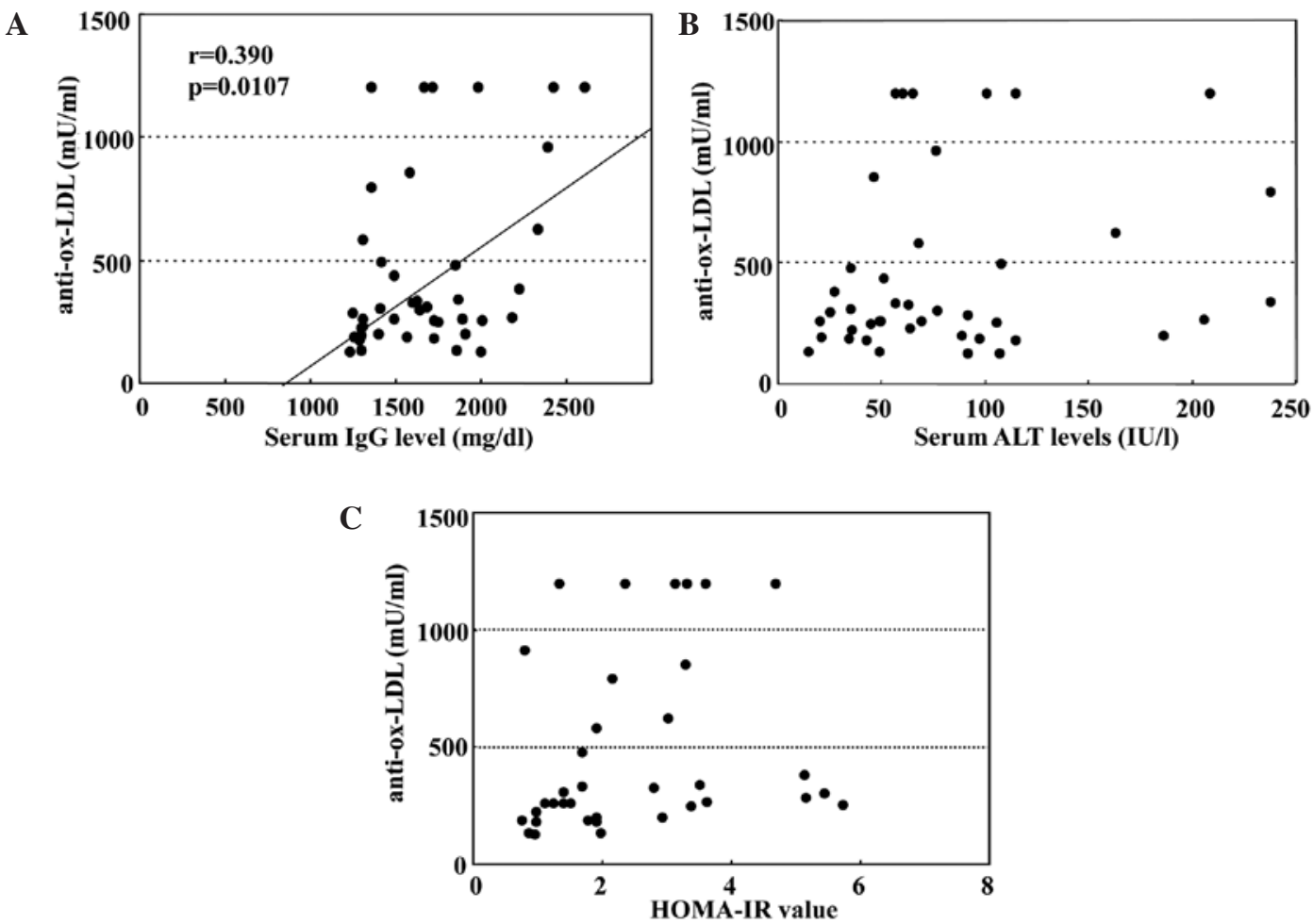

Figure 2. Relationship between the levels of anti-ox-LDL and (A) serum IgG, (B) serum ALT or (C) HOMA-IR values.

Table III. Efficacy of the antiviral treatment in patients with $\mathrm{CH}-\mathrm{C}$ of genotype $1 \mathrm{~b}$.

\begin{tabular}{lccc}
\hline & SVR $(\mathrm{n}=5)$ & Non-SVR $(\mathrm{n}=15)$ & $\mathrm{p}$-value \\
\hline Age (years) & $58.4 \pm 12.5$ & $64.7 \pm 7.7$ & $\mathrm{NS}$ \\
ALT (IU/l) & $59.0 \pm 33.0$ & $81.0 \pm 39$ & $\mathrm{NS}$ \\
Hepatic steatosis (grade 0/1/2) & $2 / 3 / 0$ & $6 / 5 / 4$ & $\mathrm{NS}$ \\
Loads of HCV-RNA (KIU/ml) & $878 \pm 971$ & $1,249 \pm 1,140$ & $\mathrm{NS}$ \\
Hepatic fibrosis (F0/F1/F2/F3) & $0 / 4 / 0 / 1$ & $0 / 3 / 0 / 12$ & $\mathrm{p}=0.0176$ \\
HAI score & $10 \pm 4.6$ & $11.8 \pm 3.9$ & $\mathrm{NS}$ \\
Anti-ox-LDL (mU/ml) & $273 \pm 118$ & $521.0 \pm 424$ & $\mathrm{NS}$ \\
\hline
\end{tabular}

$\mathrm{CH}-\mathrm{C}$, chronic hepatitis C; SRV, sustained virological response; ALT, alanine aminotransferase; HCV, hepatitis C virus; HAI, histological activity index; anti-ox-LDL, antibodies to oxidized low-density lipoprotein; NS, not significant.

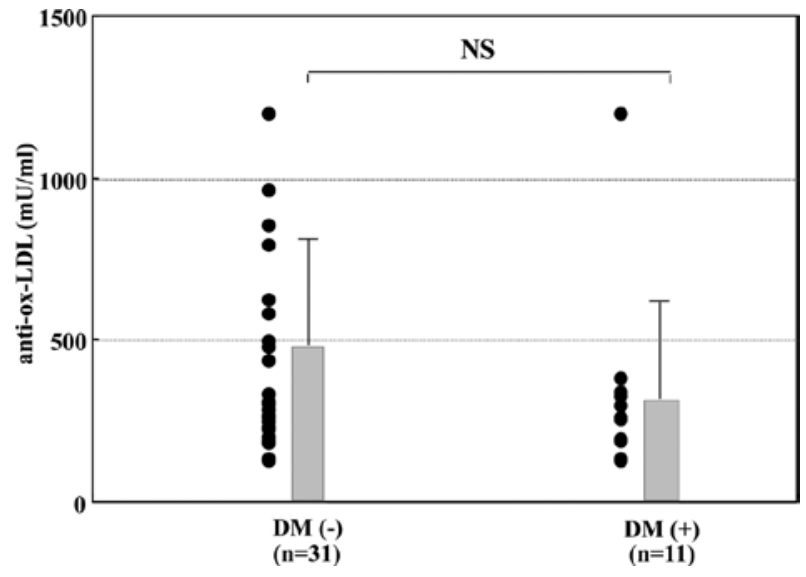

Figure 3. Relationship between the levels of anti-ox-LDL and concurrent type 2 DM. NS, not significant. contribute to the autoimmune phenomena. Accumulation of ox-LDL in the liver tissues during the process of hepatic steatosis has been postulated as a possible mechanism of autoantibody production in patients with $\mathrm{CH}-\mathrm{C}$. Persistent $\mathrm{HCV}$ infection exerts the formation of $\operatorname{ROS}$ in the liver $(1,2)$. Oxidative stress caused by $\mathrm{HCV}$ infection facilitates lipid peroxidation (3) and consequently promotes hepatic steatosis $(4,5)$. We speculated that oxidative modification of LDL induced immunogenic epitopes in the LDL molecule and that ox-LDL accumulated in the liver during the process of hepatic steatosis. The accumulation of ox-LDL may trigger the production of anti-ox-LDL. However, there were previous reports in which no correlation (29) or inverse correlation (30) was found between the levels of ox-LDL and anti-ox-LDL. Therefore, further studies are required to confirm this speculation on the production of anti-ox-LDL in patients with $\mathrm{CH}-\mathrm{C}$. 
Recently, Vidali and colleagues demonstrated that the levels of circulating IgG against malondialdehyde (MDA)albumin adducts were significantly higher in $\mathrm{CH}-\mathrm{C}$ patients with hepatic steatosis than in those without hepatic steatosis (31). This result implies that the autoimmune response to MDA, which is a product of polyunsaturated fatty acid peroxidation, is involved in the process of hepatic steatosis in patients with $\mathrm{CH}-\mathrm{C}$.

On the other hand, recent studies have found that $10-30 \%$ of patients with non-alcoholic fatty liver disease (NAFLD) or non-alcoholic steatohepatitis (NASH) have autoantibodies, including ANA and/or smooth muscle antibodies (SMA), with elevated serum IgG levels $(32,33)$. These findings suggest that hepatic steatosis or steatohepatitis are strictly associated with autoimmune reactions.

By contrast, Czaja and colleagues previously reported that $\mathrm{CH}-\mathrm{C}$ patients with hepatic steatosis had lower serum concentrations of $\mathrm{IgG}$ and a lower frequency of ANA than those of $\mathrm{CH}-\mathrm{C}$ patients without steatosis (34). However, our data in the present study are in direct opposition to their results (Table II). This difference may have been derived from the genotypes of $\mathrm{HCV}$ or the genetic backgrounds of patients with $\mathrm{CH}-\mathrm{C}$.

The association of insulin resistance with autoimmune disorder has been widely discussed. Patients with SLE frequently exhibit insulin resistance (35). Loria and colleagues showed that high titers of ANA are favorable indicators of insulin resistance in patients with NAFLD (32). We investigated the correlation between the levels of anti-ox-LDL and insulin resistance in patients with $\mathrm{CH}-\mathrm{C}$, but observed no such correlation (Fig. 2).

Previous reports have found that the emergence of nonorgan-specific autoantibodies, including ANA, SMA or parietal cell autoantibodies at baseline or an increase in their titers during antiviral treatments, appear to be a predictive indicator of a poor response in patients with $\mathrm{CH}-\mathrm{C}(36,37)$. Therefore, we examined the relationship between the levels of anti-ox-LDL and the outcomes of antiviral treatments in the $\mathrm{CH}-\mathrm{C}$ patients (Table III). However, the levels of anti-ox-LDL did not affect the outcomes of antiviral treatments in the patients with $\mathrm{CH}-\mathrm{C}$.

In conclusion, we demonstrated that hepatic steatosis is strongly associated with the emergence of anti-ox-LDL in patients with $\mathrm{CH}-\mathrm{C}$, which indicates that autoimmune responses to ox-LDL are involved in the pathogenesis of hepatic steatosis in patients with $\mathrm{CH}-\mathrm{C}$.

\section{References}

1. Koike $\mathrm{K}$ and Miyoshi $\mathrm{H}$ : Oxidative stress and hepatitis $\mathrm{C}$ viral infection. Hepatol Res 34: 65-73, 2006.

2. Okuda M, Li K, Beard MR, et al: Mitochondrial injury, oxidative stress, and antioxidant gene expression are induced by hepatitis C virus core protein. Gastroenterology 122: 366-375, 2002.

3. Farinati F, Cardin R, De Maria N, et al: Iron storage, lipid peroxidation and glutathione turn over in chronic anti-HCV positive hepatitis. J Hepatol 22: 449-456, 1995.

4. Lonardo A, Adinolfi LE, Loria P, et al: Steatosis and hepatitis C virus: mechanisms and significance for hepatic and extrahepatic disease. Gastroenterology 126: 588-597, 2004.

5. Moriya K, Yotsuyanagi H, Shintani Y, et al: Hepatitis C virus core protein induces hepatic steatosis in transgenic mice. J Gen Virol 78: 1527-1531, 1997.

6. Devenyi P, Rutherdale J, Sereny G and Olin JS: Clinical diagnosis of alcoholic fatty liver. Am J Gastroenterol 54: 597-602, 1970.
7. Murthy VK and Shipp JC: Hepatic steatosis in diabetes: increased synthesis of triglycerol and impaired feedback regulation. Trans Assoc Am Physicians 94: 322-332, 1981.

8. Hill RB and Rude JFP: Cortisone-induced lipaemia and hepatic steatosis in the male rat. Nature 210: 733, 1966.

9. Hourigan LF, Macdonald GA, Purdie D, et al: Fibrosis in chronic hepatitis $\mathrm{C}$ correlates significantly with body mass index and steatosis. Hepatology 29: 1215-1219, 1999.

10. Adinolfi LE, Gambardella M, Andreana A, Tripodi MF, Utili R and Ruggiero G: Steatosis accelerates the progression of liver damage of chronic hepatitis $\mathrm{C}$ patients and correlates with specific HCV genotype and visceral obesity. Hepatology 33: 1358-1364, 2001.

11. Monto A, Alonzo J, Watson JJ, Grunfeld C and Wright TL: Steatosis in chronic hepatitis C: relative contribution of obesity, diabetes mellitus, and alcohol. Hepatology 36: 729-736, 2002.

12. Hui JM, Kench J, Farrell GC, et al: Genotype-specific mechanisms for hepatic steatosis in chronic hepatitis $\mathrm{C}$ infection. $\mathrm{J}$ Gastroenterol Hepatol 17: 873-881, 2002.

13. Poynard T, Ratziu V, McHutchison J, et al: Effect of treatment with peginterferon or interferon alfa- $2 \mathrm{~b}$ and ribavirin on steatosis in patients infected with hepatitis C. Hepatology 38: 75-85, 2003.

14. Fartoux L, Poujol-Robert A, Guechot J, Wendum D, Poupon R and Serfaty L: Insulin resistance is a cause of steatosis and fibrosis progression in chronic hepatitis C. Gut 54: 1003-1008, 2005.

15. Camma C, Bruno S, Marco VD, et al: Insulin resistance is associated with steatosis in nondiabetic patients with genotype 1 chronic hepatitis C. Hepatology 43: 64-71, 2006.

16. Soresi M, Tripi S, Franco V, et al: Impact of liver steatosis on the antiviral response in hepatitis $\mathrm{C}$ virus-associated chronic hepatitis. Liver Int 26: 1119-1125, 2006.

17. Westin J, Lagging M, Dhillon AP, et al: Impact of hepatic steatosis on viral kinetics and treatment outcome during antiviral treatment of chronic HCV infection. J Viral Hepat 14: 29-35, 2007.

18. Ohta K, Hamasaki K, Toriyama K, et al: Hepatic steatosis is a risk factor for hepatocellular carcinoma in patients with chronic hepatitis C virus infection. Cancer 97: 3036-3043, 2003.

19. Kumar D, Farrell GC, Kench J and George J: Hepatic steatosis and the risk of hepatocellular carcinoma in chronic hepatitis $\mathrm{C}$. J Gastroenterol Hepatol 20: 1395-1400, 2005.

20. Pawlotsky JM, Yahia MB, Andre C, et al: Immunological disorders in $\mathrm{C}$ virus chronic active hepatitis: a prospective casecontrol study. Hepatology 19: 841-848, 1994.

21. Manns MP and Rambusch EG: Autoimmunity and extrahepatic manifestations in hepatitis $\mathrm{C}$ virus infection. J Hepatol 31: S39-S42, 1999.

22. Vaarala O, Alfthan G, Jauhiainen M, et al: Crossreaction between antibodies to oxidized low-density lipoprotein and to cardiolipin in systemic lupus ery thematosus. Lancet 341: 923-925, 1993.

23. Hsu RM, Devaraj S and Jialal I: Autoantibodies to oxidized lowdensity lipoprotein in patients with type 2 diabetes mellitus. Clin Chim Acta 317: 145-150, 2002.

24. Lau JY, Davis GL, Kinffen J, et al: Significance of serum hepatitis C virus RNA levels in chronic hepatitis C. Lancet 341: 1501-1504, 1993.

25. Simmonds P, Alberti A, Alter HJ, et al: A proposed system for nomenclature of hepatitis C viral genotypes. Hepatology 19: 1321-1324, 1994.

26. Brunt EM, Janney CG and Bisceglie D: Nonalcoholic steatohepatitis: a proposal for grading and staging the histological lesions. Am J Gastroenterol 94: 2467-2474, 1999.

27. Ichida F, Tsuji T, Omata M, et al: New Inuyama classification: new criteria for histological assessment of chronic hepatitis. Int Hepatol Commun 6: 112-119, 1996.

28. Knodel RG, Ishak KG, Black WC, et al: Formulation and application of a numerical scoring system for assessing histological activity in asymptomatic chronic active hepatitis. Hepatology 1: 431-435, 1981.

29. Becarevic M, Singh S and Majkic-Singh N: Oxidized LDL, anti-oxidized LDL and anti-annexin A5 antibodies in primary antiphospholipid syndrome. Clin Lab 54: 97-101, 2008.

30. Shoji T, Nishizawa Y, Fukumoto M, et al: Inverse relationship between circulating oxidized low-density lipoprotein (oxLDL) and anti-oxLDL antibody levels in healthy subjects. Atherosclerosis 148: 171-177, 2000. 
31. Vidali M, Tripodi MF, Ivaldi A, et al: Interplay between oxidative stress and hepatic steatosis in the progression of chronic hepatitis C. J Hepatol 48: 399-406, 2008.

32. Loria P, Lonardo A, Leonardi F, et al: Non-organ-specific autoantibodies in nonalcoholic fatty liver disease: prevalence and correlates. Dig Dis Sci 48: 2173-2181, 2003.

33. Adams LA, Lindo KD and Angulo P: The prevalence of autoantibodies and autoimmune hepatitis in patients with nonalcoholic fatty liver disease. Am J Gastroenterol 99: 1316-1320, 2004.

34. Czaja AJ, Carpenter HA, Santrach PJ and Moore SB: Host- and disease-specific factors affecting steatosis in chronic hepatitis C. J Hepatol 29: 198-206, 1998.
35. Escarcega RO, Garcia-Carrasco M, Fuentes-Alexandro S, et al: Insulin resistance, chronic inflammatory state and the link with systemic lupus erythematosus-related coronary disease. Autoimmun Rev 6: 48-53, 2006.

36. Gatselis NK, Georgiadou SP, Koukoulis GK, et al: Clinical significance of organ- and non-organ-specific autoantibodies on the response to anti-viral treatment of patients with chronic hepatitis C. Aliment Pharmacol Ther 24: 1563-1573, 2006.

37. Wasmuth HE, Stolte C, Geier A, et al: The presence of nonorgan-specific autoantibodies is associated with a negative response to combination therapy with interferon and ribavirin for chronic hepatitis C. BMC Infect Dis 4: 1-8, 2004. 